\title{
NUMERICAL STUDY FOR RELIABILITY ASSESSMENT OF A CORRODING PIPE TO FLANGE WELD JOINT OVER ITS LIFETIME
}

\author{
Mourad Nahal $^{1}$ - Abdelaziz Lakehal ${ }^{1 *}$ - Rabia Khelif ${ }^{2}$ \\ ${ }^{1}$ Department of Mechanical Engineering, Mohamed Chérif Messaadia University, P.O. Box 1553, Souk-Ahras, 41000, \\ Algeria \\ ${ }^{2}$ Badji Mokhtar University, BP 12, Annaba, 23000, Algeria

\begin{tabular}{l}
\hline ARTICLE INFO \\
\hline Article history: \\
Received 8.11 .2018$. \\
Received in revised form 28.1.2020. \\
Accepted 19.2.2020. \\
\hline Keywords: \\
Pipeline Corrosion \\
Weld joint \\
Reliability \\
Finite element model \\
Monte Carlo \\
Form \\
\hline DOI: https://doi.org/10.30765/er.1371 \\
\hline
\end{tabular}

\begin{abstract}
:
Numerical model of a corroded weld joint connecting pipe to flange using a finite element method was developed, and coupled with usual stress models. The structure material has been characterized experimentally. Monte Carlo simulations, FORM and SORM methods have been applied for estimating reliability and failure probability under corrosion and residual stress effects. A numerical case with various corrosion rates was conducted to determine the reliability of the welded connection pipe to flange. The obtained results show that the heat affected zone is very sensitive to corrosion effects due to the welding process.
\end{abstract}

\section{Introduction}

The pipelines are considered one of the safest and cheapest tools conveying oil and gas in the worldwide nowadays. In Algeria, more than $98 \%$ of transporting oil and natural gas production is currently being ensured by pipelines. Within the pipeline networks, pipe to flange is the most used connection which can be found [1]. Unfortunately, the number of accidents due to aging pipelines conveying hydrocarbon have significantly increased. In fact, the pipelines are subjected to various hazardous risks which can affect their safety service, such as fatigue due to aging pipeline [2], corrosion, cracks and dents which can have significant social and economic impact.

Corrosion is considered as one of the biggest problems which can affect pipeline integrity [3], especially the heat affected zone such as welded joint connection. Regarding the corrosion modeling, several models have been developed and used by researchers within the last few years [4]. The residual stresses analysis is a mandatory step for designing pipelines, as well as the estimation of their reliability in real service conditions. Manufacturing pipelines with mechanical processes, chemical and heat treatments occurs in most cases as residual stresses. This is usually due to an imbalance of the material external and internal conditions. Residual stresses generation can also be influenced by time, temperature, deformation and microstructure interactions. Material characteristics influencing the residual stresses development can include thermal conductivity, thermal capacity, thermal expansion, modulus of elasticity and plasticity, Poisson ratio, thermodynamics and kinetics of transformations.

Zhang and Cheng [5] conducted a research where they found that weld heat affected zone have much greater anodic dissolution current in X70 steel pipeline. Increasing of the applied stress enlarged the anodic dissolution of welded X70 steel, mainly the heat-affected zone. Several works [5-7] have found that corrosion susceptibility of heat affected zones (HAZ) is in fact, enhanced due to non-uniform temperature effect applied during the welding process. Corrosion of the welded area has been the subject of various research works [7-9]. Corrosion and intergranular corrosion were improved resulting from GBA and WA formation. In addition, it has been observed that the corrosion rate of the heating affected zone in mild steel increases when the Mn content of the steel

\footnotetext{
* Corresponding author

E-mail address: lakehal21@yahoo.fr
} 
increases. Furthermore, when welding decreases, the used heat input is equivalent, and it can significantly produce harmful effects on pipe-flange joints' life such as decreasing the applied stress resistance of a structure.

The microstructure effect is illustrated by Clover et al. [10] where an experiment process was exploited. It was found that the fine grained bainite-ferrite have better stress concentration factor (SCF) than the ferrite-pearlite structure demonstrating the more useful of fine grained bainite-ferrite in steel grad. The high corrosion sensitivity of HAZ can be connected with the elemental segregation and coarse grain which was the result of Ren et al. [11] work. The welded joint proprieties and microstructures relation becomes an easy subject for researchers through development of simulation technique in the welding field [12-14].

The increased number of associated publications in the existing literature prompted us to conduct a research on reliability of pipe-flange welded joint under the corrosion effect. Several research papers studied probabilistic reliability of corroded pipeline such as the works conducted by Zhou [15] and Hasan et al. [16], Teixeira et al. [17], and an important contribution has been presented, but in most cases just a regular part of pipelines was treated. At the present time, numerical methods are most useful tools by main researchers, particularly for the gain time which can be saved. In fact, modeling the corrosion effect on aging pipelines integrity using numerical tools by applying finite element modulation can be applied for assessing and evaluating reliability and failure probability of any structure [18-23].

The aim of the present work is to estimate time-dependent reliability of a corroding pipe to flange weld joint over its lifetime using numerical models by applying finite element modeling. Firstly, an experimental study was conducted; the goal was to characterizing the pipeline material to defining: the yield strength, the ultimate strength and the Young modulus. Furthermore, a numerical model of corroded pipe-flange weld joint was developed and coupled with an empirical mechanical behavior model which was proposed. A probabilistic model is also developed to provide corrosion parameters, allowing to predict a real impact on the weld joint lifetime. The reliability indexes and probability of failure for various corrosion rates with and without issued residual stress were computed using enhanced Monte Carlo simulation and first-order reliability method. The found results are very interesting and can be used for a practical case.

\section{Experimental part}

\subsection{Characterization of the pipeline material}

During the product development, it is necessary to check the reliability at the different stages of the project. In general, we started with an ambitious goal to reach an operational reliability level which can be accepted by users. For this, a series of tests must be conducted by TSS unit (seamless tubing) according to the environment, the operation and the reliability requirements.

When manufacturing a new product in TSS unit, it is very often necessary to control his mechanical characteristics such as: rupture strength, response to a static or dynamic solicitation, elasticity characteristics, or its limits in compression. The different dimensional characteristics of the modeled pipeline are given in Table 1.

Table 1. The pipeline model input data (case of deterministic pipeline characteristics).

\begin{tabular}{|l|c|c|c|c|}
\hline Variable & Symbol & Corrosion rate & Mean value & Coefficient of variation \\
\hline Pipe diameter & $D(\mathrm{~mm})$ & & 508 & - \\
\hline Flange diameter & $D_{\mathrm{fl}}(\mathrm{mm})$ & & 800 & - \\
\hline Wall thickness & $e_{0}(\mathrm{~mm})$ & & 9.5 & 0.07 \\
\hline Yield strength & $\sigma(\mathrm{MPa})$ & & 485 & 0.25 \\
\hline Internal pressure & $P(\mathrm{MPa})$ & & 4 & 0.016 \\
\hline \multirow{3}{*}{ Corrosion rate } & \multirow{2}{*}{$K$} & Low & 0.16 & 0.037 \\
\cline { 3 - 5 } & & Moderate & 0.37 & 0.067 \\
\cline { 3 - 5 } & $N$ & High & 0.67 & - \\
\hline Corrosion parameters & $\delta$ & & 0.53 & 0.15 \\
\hline Model error & $A$ & & 1 & 0.20 \\
\hline Residual stress variation factor & & & 1 & \\
\hline
\end{tabular}




\subsection{Testing machine}

Different mechanical tests are performed on a machine designed to test steels, TSS unit use «Zwick/Roell " machine (Figure 1 and Figure 2) which is a special machine that consists of a rigid frame, consisting of two guide columns and two horizontal crosspieces (one fixed and the other mobile). The movable cross member and the base plate are provided with jaws between which the part to be tested is attached.

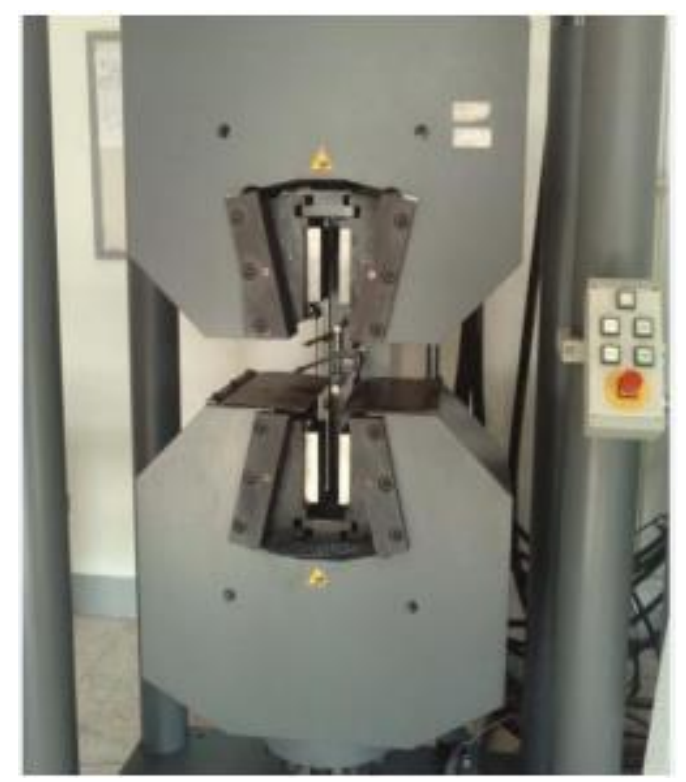

Figure 1. The Zwick / Roell testing used machine.

The TSS workshop (seamless tube), in which the study was conducted, carries out a number of quality tests on its production. The goal was to determine the yield strength, the ultimate strength and the Young modulus. The obtained results are as follows:

$$
E=206 \mathrm{GPa} ; F_{\mathrm{y}}=485 \mathrm{MPa} ; R=520 \mathrm{MPa}
$$

with $E$ the Young modulus, $F_{\mathrm{y}}$ the yield strength and $R$ the ultimate strength.
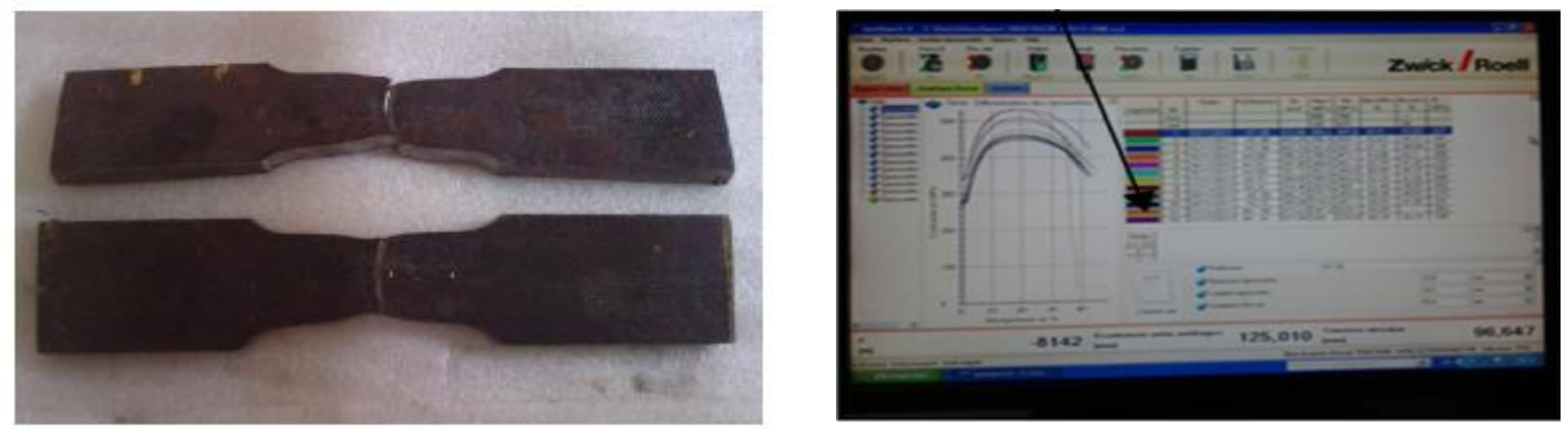

Figure 2. Testing specimens and the machine software. 


\section{Mechanical model}

\subsection{Corrosion model}

In practice, corrosion has in general tow forms such as uniform corrosion and localized corrosion; for modeling the loss in wall thickness with the exposure time of an aging pipeline a power low model is in general applied in uniform corrosion $[24,25]$ which is given by:

$$
t_{\mathrm{c}}=K t^{n}
$$

With $t_{\mathrm{c}}$ is the loss in wall thickness over time, $K$ and $n$ parameters depending on environmental condition, $t$ is the elapsed life time.

Regarding to localized corrosion field, the time dependent depth $e_{\mathrm{lc}}(t)$ and length $l_{\mathrm{lc}}(t)$ of corrosion defect can take the form [26]:

$$
\begin{gathered}
e_{\mathrm{lc}}(t)=\left(k_{\mathrm{uc}}+\alpha_{\mathrm{lc}} \Delta k_{\mathrm{lc}}\right) t^{n} \\
l_{\mathrm{lc}}(t)=\gamma_{\mathrm{lc}}\left(k_{\mathrm{uc}}+\alpha_{\mathrm{lc}} \Delta k_{\mathrm{lc}}\right) t^{n}
\end{gathered}
$$

with $e_{\mathrm{lc}}(t)$ and $l_{\mathrm{lc}}(t)$ representing the localized corrosion depth and length, $\gamma_{\mathrm{lc}}$ is the length-to-depth ration, $k_{\mathrm{uc}}$ and $\mathrm{n}$ are the corrosion constants, $\alpha_{\mathrm{lc}}$ is the localized corrosion fraction, and $\Delta k_{\mathrm{lc}}$ represents the specific rate of localized corrosion.

\subsection{Pipe-flange weld joint finite element model}

A geometric model of pipe-flange corroded weld joint was proposed (Table 2) under the software by using finite element modeling (Figure 3). In this study the finite element model of pipe-flange corroded weld joint is simplified to 2-D ax symmetrical analysis.

An element with 6 nodes having tow degrees of freedom at each node was chosen for 2-D model. A quadratic displacement was applied to properly model irregular zone (corroded area in our case). For the boundary conditions the pipe was blocked along the (yy) axis and it's free for (xx) axis. In total, the corroded pipe model has 17,976 nodes with a maximum von Misses stress of $295.81 \mathrm{MPa}$, with $7 \mathrm{~mm}$ of a corrosion depth and 4 bar service pressure.

Table 2. Pipeline dimensional characteristics.

\begin{tabular}{|l|l|}
\hline Parameter & Type / Value \\
\hline Pipeline & API 5L X70 \\
\hline$F_{\mathrm{y}}$ & $485 \mathrm{MPa}$ \\
\hline Outer diameter $D$ & $508 \mathrm{~mm}$ \\
\hline Pipeline wall thickness $e_{0}$ & $9.5 \mathrm{~mm}$ \\
\hline Ultimate strength & $520 \mathrm{MPa}$ \\
\hline Poisson Coefficient $v$ & 0.3 \\
\hline Young modulus $E$ & $206 \mathrm{GPa}$ \\
\hline Service pressure & $4 \mathrm{bar}$ \\
\hline
\end{tabular}

The pipe to flange weld joint geometry model is presented in Figure 3. The corrosion impact on the pipe to flange weld joint behavior will be studied in the next section. 

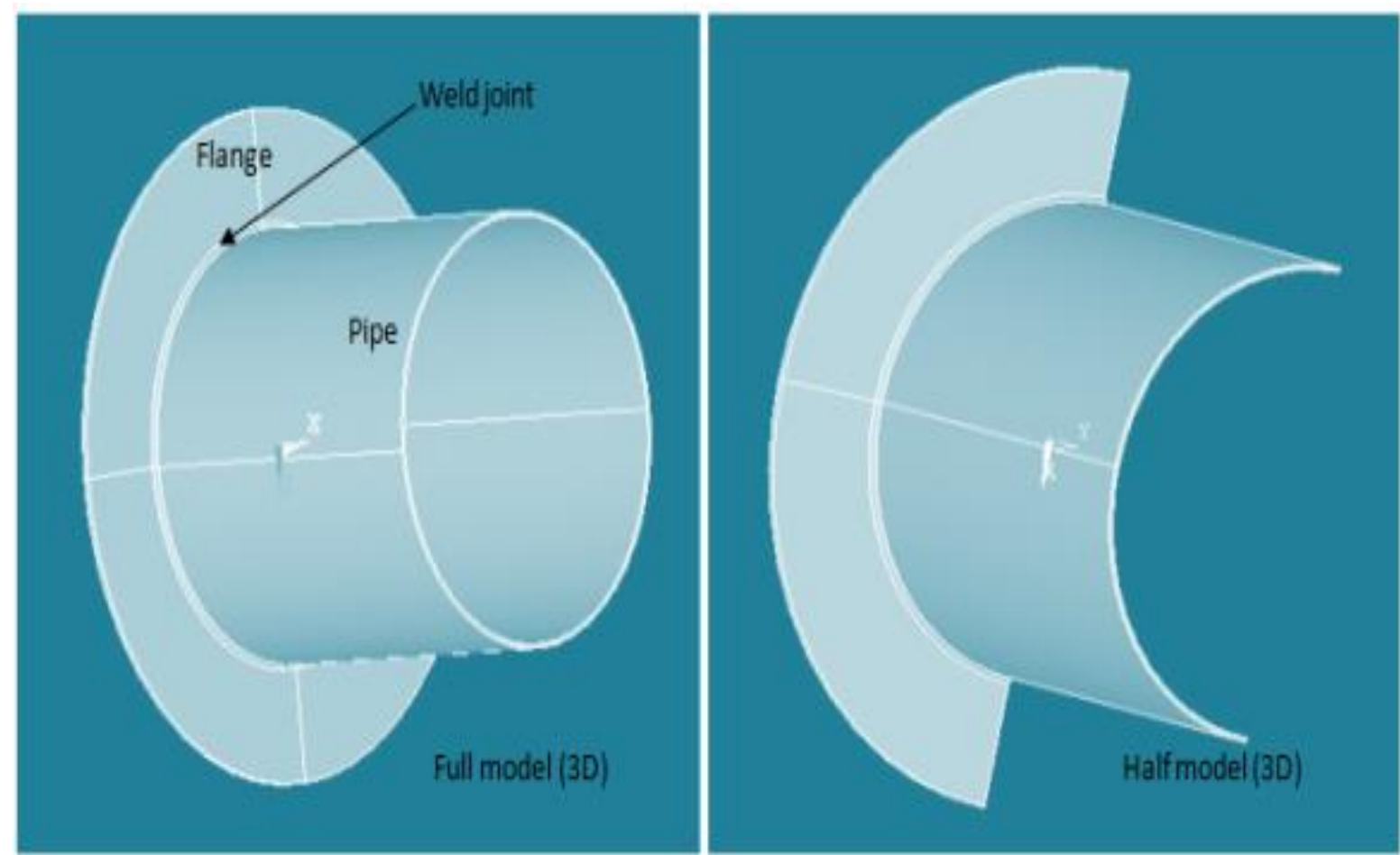

Figure 3.a. Pipe-flange weld joint geometry and finite element model.
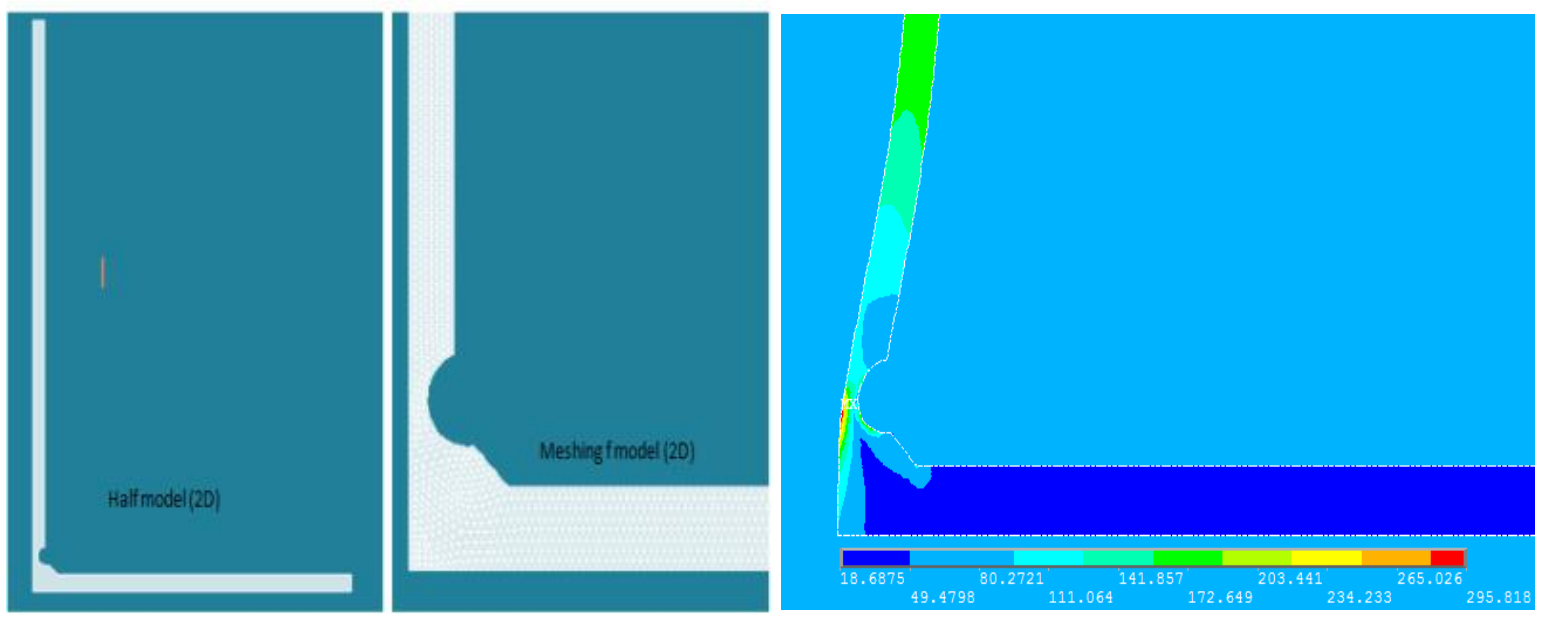

Figure 3.b. Pipe-flange weld joint 2-D finite element model with solution.

\subsection{Mechanical behavior}

The mechanical behavior of the pipe-flange corroded weld joint under the operation service pressure (4 MPa) and corrosion effect is shown in Figure. 4 The corrosion depth increased by $1 \mathrm{~mm}$ in each computing case. The evolution of the Von Misses stress is also represented. 


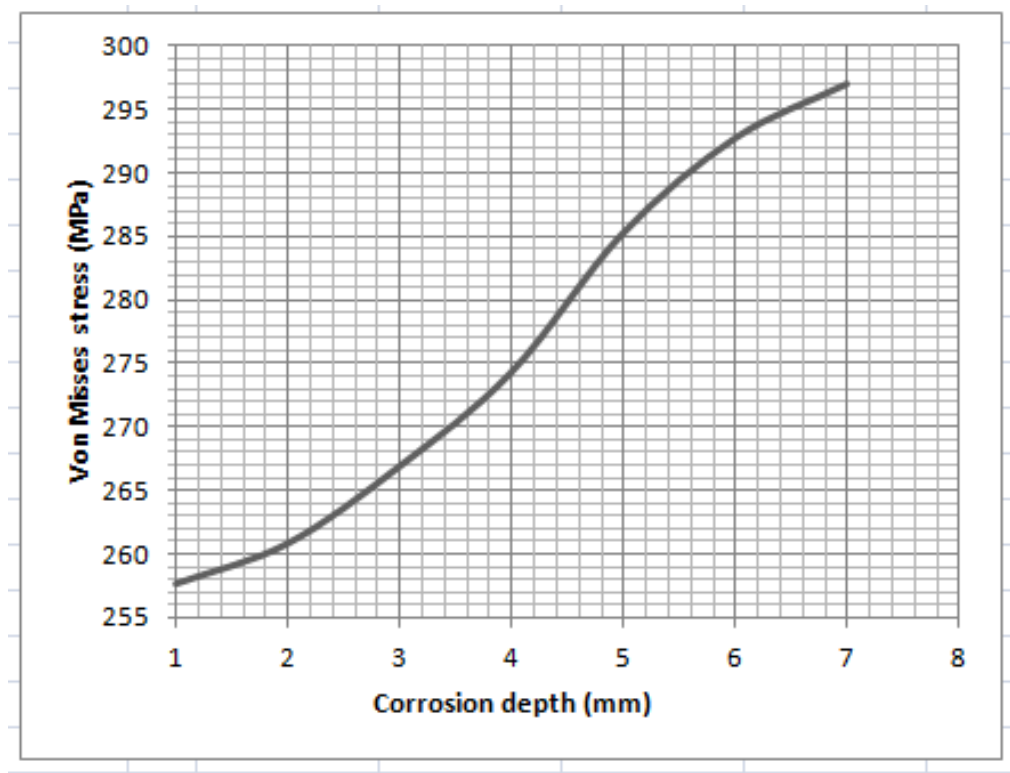

Figure 4. The Von Mises stress evolution vs. corrosion depth for pipe-flange corroded weld joint.

The curve presented in Figure 4 shows the Von Misses stress evolution vs. corrosion depth of pipe to flange corroded weld joint. It can be seen that there is a proportionally increasing relationship. According to the presented curve, the empirical mechanic model is given by:

$$
\begin{gathered}
\sigma(t)=250.49+5.30 d(t)+0.23 d^{2}(t) \\
d(t)=e_{\mathrm{lc}}(t)+l_{\mathrm{lc}}(t)
\end{gathered}
$$

with $d(t)$ the loss in wall thickness over time (these relationships are specific for the considered pipe dimensions).

\subsection{Residual stress evaluation}

For assessing residual stresses [27], destructive and nondestructive techniques can be used, but a distinction between them should be made. Ruibin and Yiliang define the residual stresses in pipelines using the following formula [25]:

$$
\sigma_{\mathrm{RS}}=0.21 \sigma_{\mathrm{y}}
$$

where $\sigma_{\mathrm{RS}}$ the residual stress, $\sigma_{\mathrm{y}}$ the yield strength, which is in our case $485 \mathrm{MPa}$ for X70 steel material constitutes the pipeline subject of this study.

\section{Reliability analysis}

Reliability analyses of the aging pipelines subjected to corrosion have been studied by a large number of researchers who applied various probabilistic standards [23-26]. A very few works in literature include the reliability analysis of weld joint, and this is why this was the fact of this study. The most widely used standards for assessing pipelines failure pressure are ASME B31G, modified ASME B31G, DNV-99, etc. The modified ASME B31G is largely applied in the existing standards of industry. In fact, the most widely used method for estimating reliability and failure probability of structure is Monte Carlo (MC). Naess et al and other researchers 
[27-29] further explain and describe the method with more detail. This method is aiming to reduce the cost of computational of crud MC simulation. The failure probability is obtained by using the following relationship:

$$
P_{\mathrm{f}}=\frac{N_{\mathrm{f}}}{N}
$$

with $N_{\mathrm{f}}$ is number of the failed simulation, $N$ is the total number of simulation.

\subsection{Limit state function}

A limit state function is applied for evaluating the reliability of pipe-flange corroded weld joint, which is given in most cases as bellow:

$$
G(t)=\sigma_{\mathrm{y}}-\sigma_{\mathrm{V}}
$$

Where: $\boldsymbol{\sigma}_{\mathrm{V}}$ is the Von Mises stress, $\boldsymbol{\sigma}_{\mathbf{y}}$ is the yield strength, when $\boldsymbol{G}(\boldsymbol{t})>\mathbf{0}$, the structure is can fulfill; $\boldsymbol{G}(\boldsymbol{t})<$ $\mathbf{0}$ the structure (pipeline) is failure. By replacing the stress expressions, the limit state function became:

$$
G(t)=\sigma_{\mathrm{y}}-\delta\left[p \cdot\left[\left(\left(250.49+5.30 d(t)+0.23 d^{2}(t)+\alpha \cdot \sigma_{\mathrm{RS}}\right)\right)\right]\right]
$$

$\delta$ represents the model error coefficient, and $\alpha$ is the residual stress variation factor.

The probability of failure is defined as:

$$
f(t)=P\left[G\left(x_{i}, t\right) \leq 0\right]=\Phi(-\beta(t))
$$

where $\Phi$ is the standard normal cumulated probability, and $\beta$ the reliability index denoted as below:

$$
\beta=\frac{\mu_{\mathrm{G}}}{\sigma_{\mathrm{G}}}=\frac{\mu_{\mathrm{y}}-\mu_{\mathrm{v}}}{\sqrt{\sigma_{\mathrm{y}}^{2}+\sigma_{\mathrm{v}}^{2}}}
$$

where $\mu_{\mathrm{G}}, \sigma_{\mathrm{G}}$, stand for the mean and standard deviation of $G(t)$ limit state function also applied the failure function, $\mu_{\mathrm{y}}, \mu_{\mathrm{v}}$ represent respectively the mean of the Von Mises stress and yield stress.

\subsection{Numerical case}

A numerical is used for illustrating the above methodology; different dimensional characteristics are mentioned in Table 2. With outer diameter $D$ of pipe, $D_{\mathrm{fl}}$ the flange diameter and nominal wall thickness $e_{0}$, is subjected to internal pressure $P$. The pipeline steel is X70 quality with nominal yield strength $\sigma_{\mathrm{y}}$, the input data are provided in Table 1, in which the random variables are considered as normally distributed. 
4.3 Results and discussion

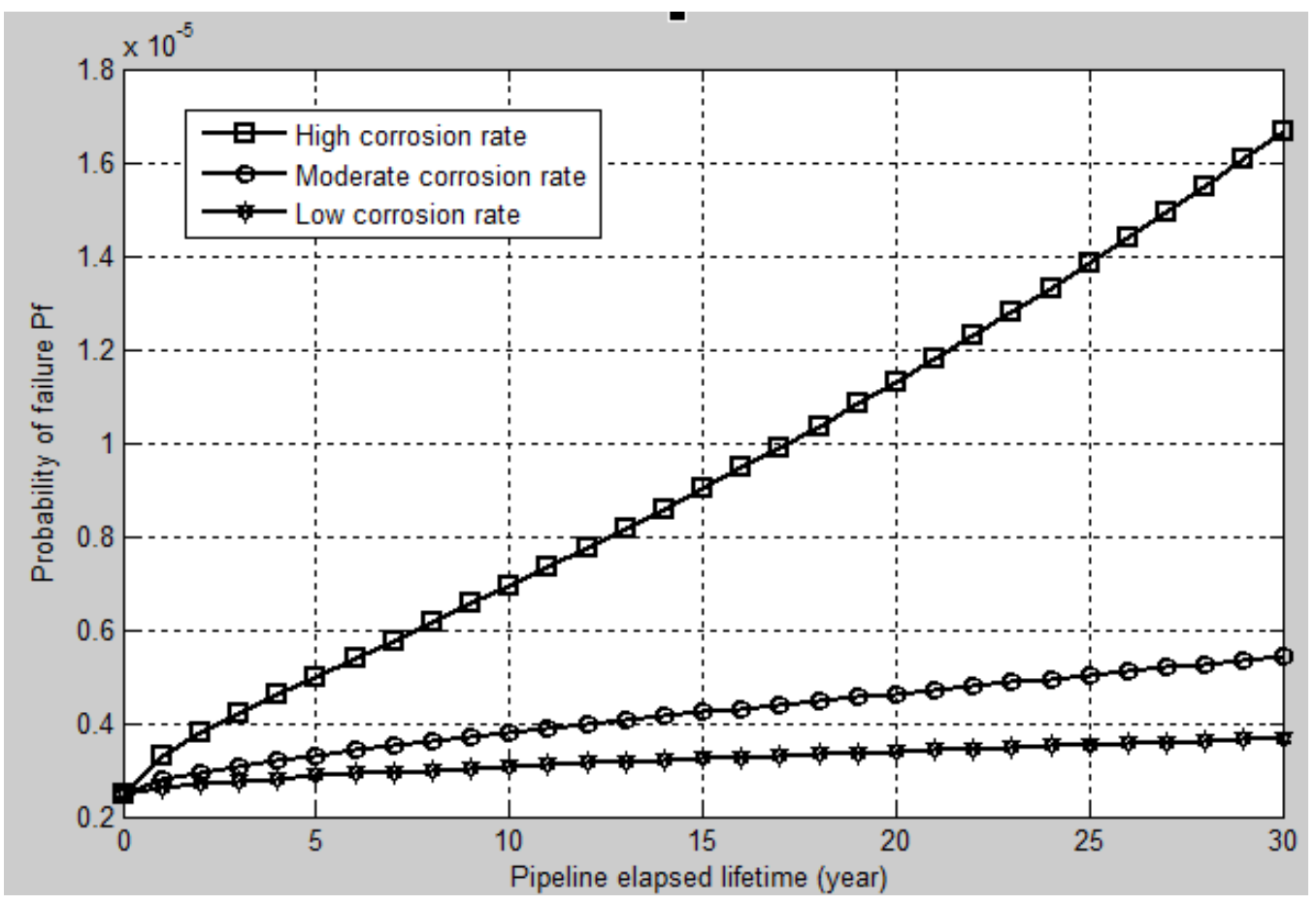

Figure 5. Probability of failure as a function of pipeline elapsed lifetime and without residual stress.

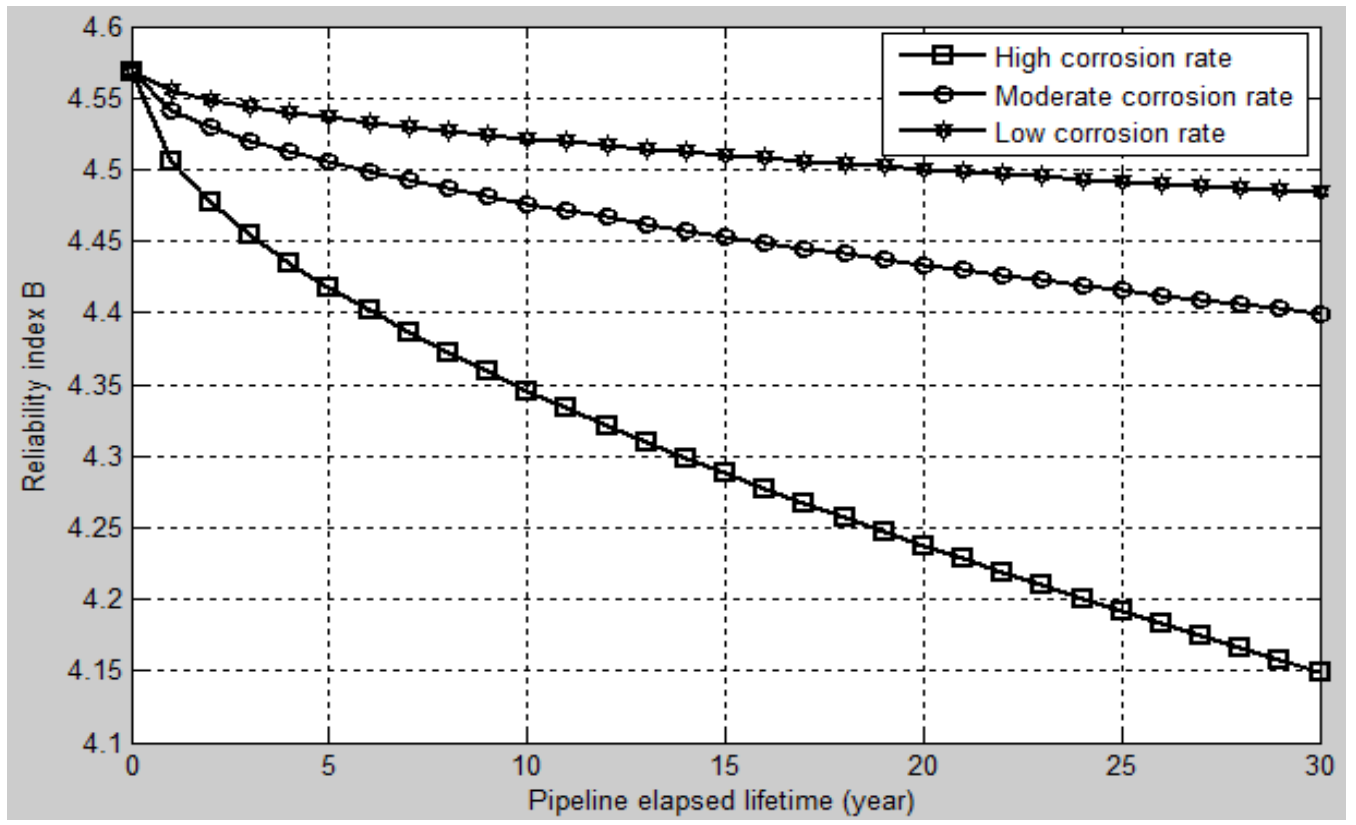

Figure 6. Reliability index as a function of pipeline elapsed lifetime and with residual stress.

Failure probability of pipe-flange corroded weld joint evolution as a function of structure elapsed life time was illustrated in Figure 5. It can be seen that the failure probability has a rapid increase in time in the case of high corrosion rate and the curve is assumed to an exponential function. On the other hand, in the tow rest cases (moderate and low corrosion rates) it can be observed that the curve assumed a linear function, with very slow increase in time. In fact, the founded results validate the harmful effects of corrosion, especially in high corrosion rate. The curves presented in Figure 6, show the reliability indexes evolution of structure integrity elapsed lifetime. A slow decrease can be observed in moderate and low corrosion rates cases, although a very 
rapid decrease can be shown in the high corrosion rate case. An inversely proportional relationship exists between reliability and corrosion depth effect.

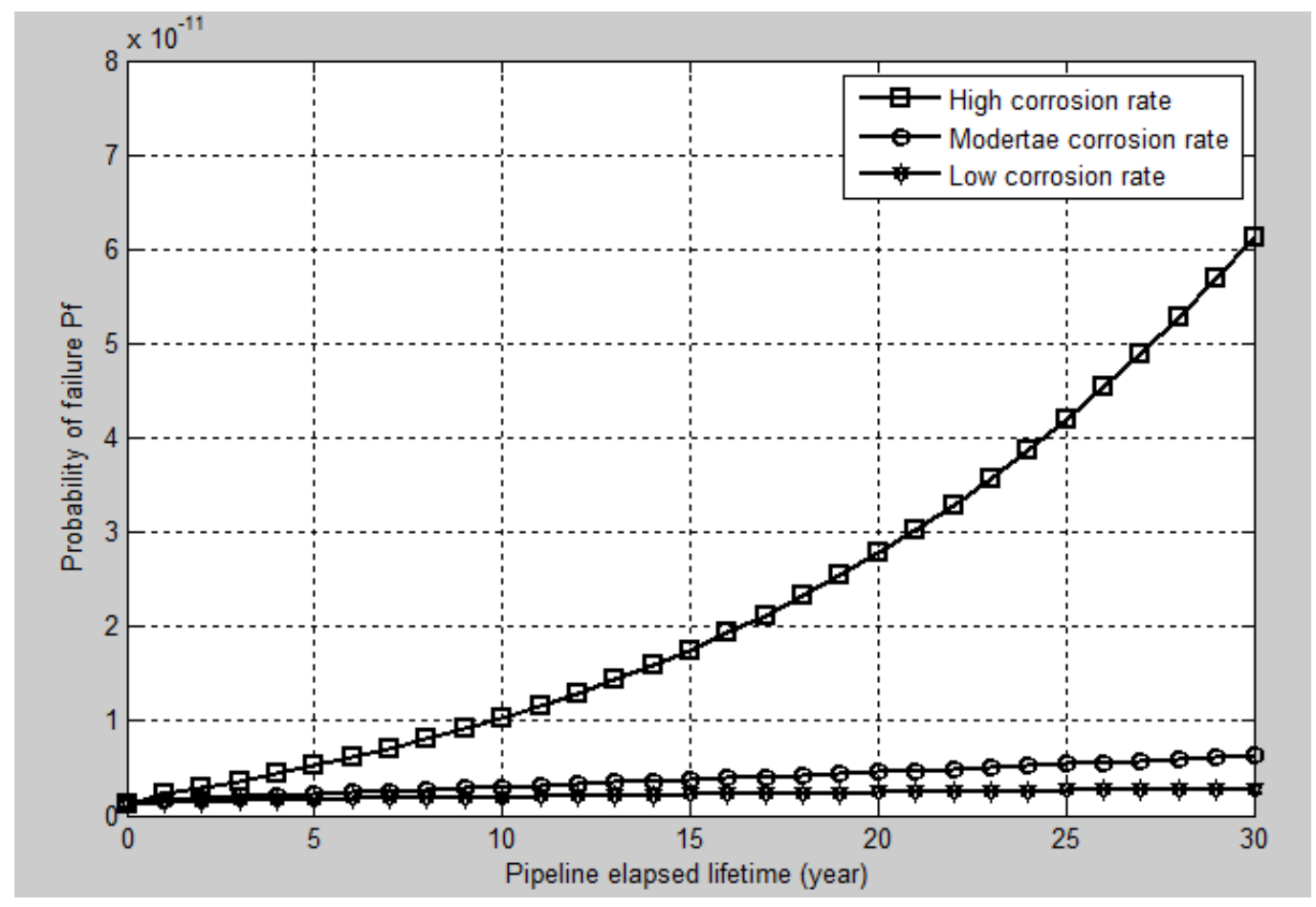

Figure 7. Probability of failure as a function of pipeline elapsed lifetime and without residual stress.

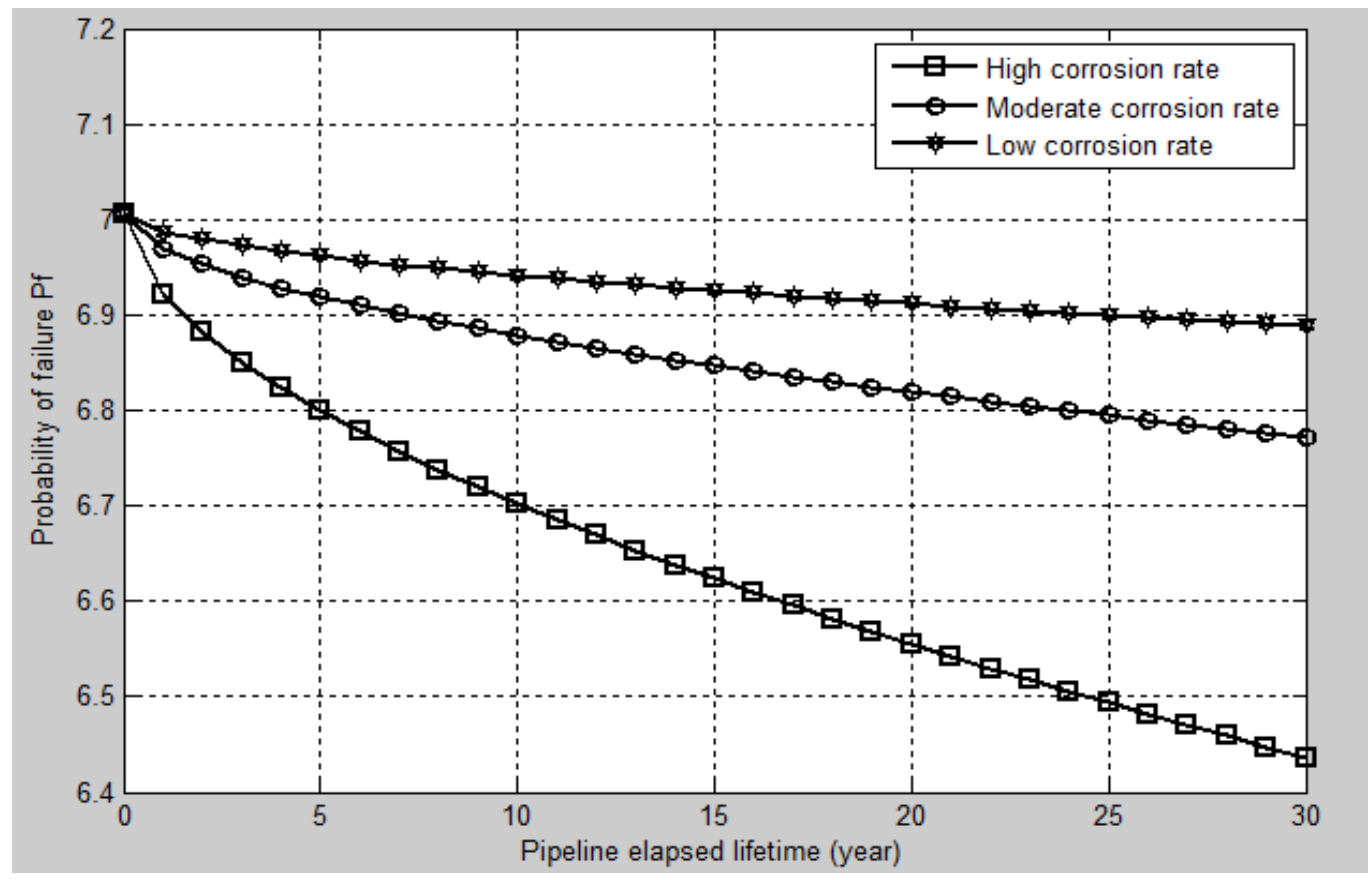

Figure 8. Reliability index as a function of pipeline elapsed lifetime and without residual stress.

Instead, both effects of corrosion and residual stress Figure 7 and Figure 8 show respectively the failure probability and reliability indexes of pipe-flange corroded weld joint evolution in time without residual stress. It can be observed, that the failure probability values are lesser than the cases where the residual stress was 
taken in account. The same observations can be found in reliability indexes. These can gives us an idea about the harmful impact of residual stress on the structure integrity, which can generate very big disasters on humans and the environment.

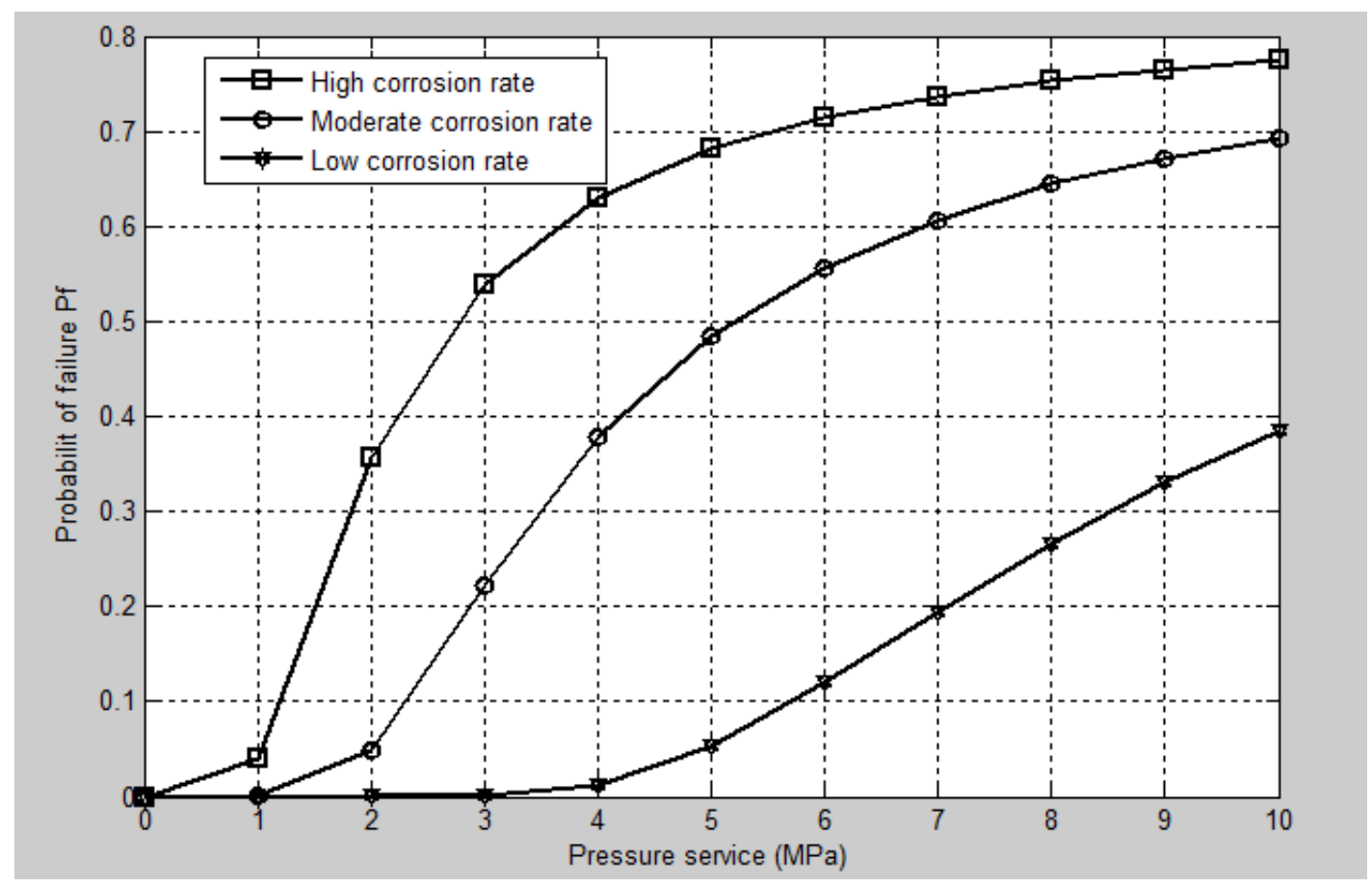

Figure 9. Probability of failure as a function of pipeline service pressure.

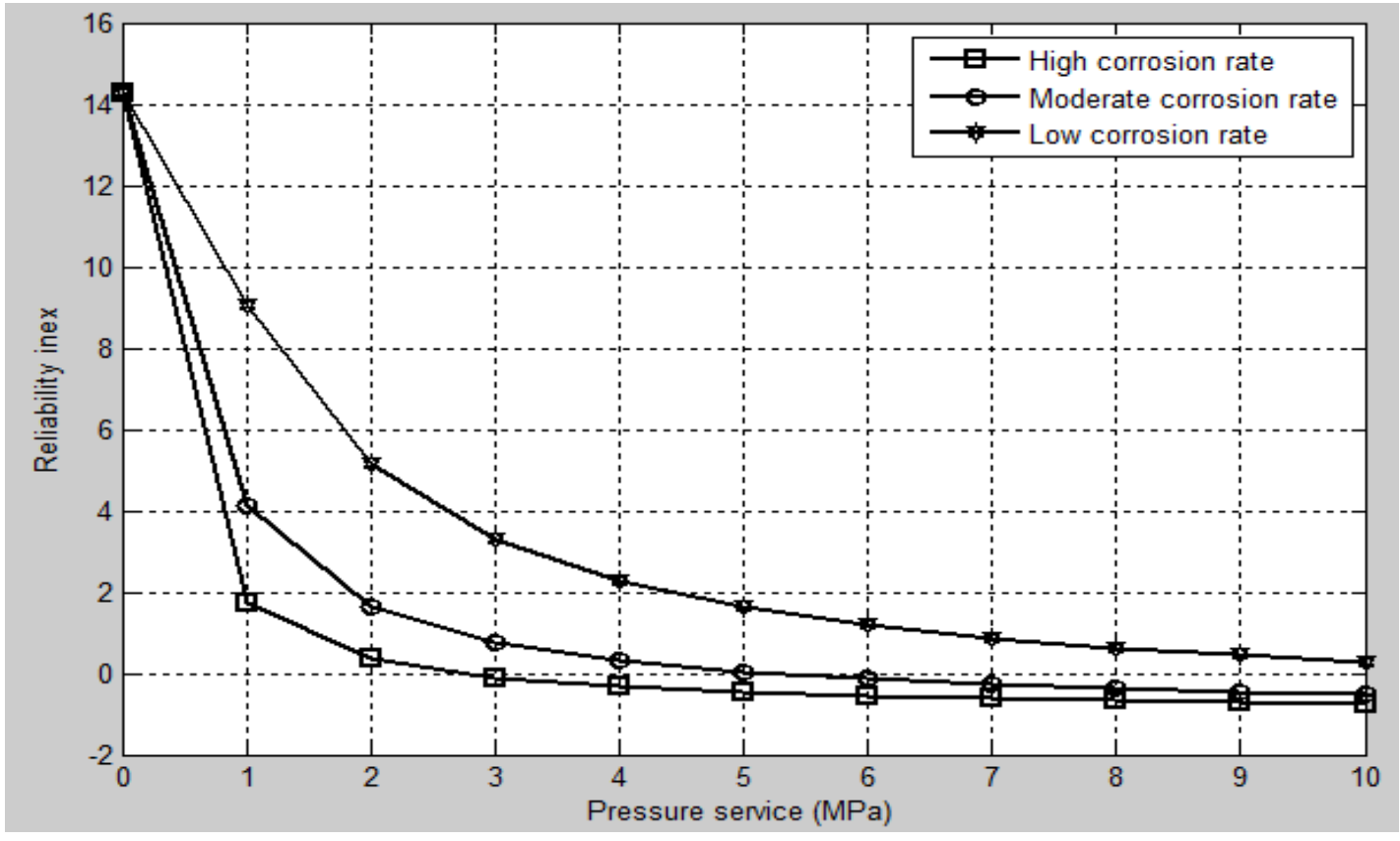

Figure 10. Reliability index as a function of pipeline service pressure.

The pressure service impact is also studied which is illustrated in Figure 9 and Figure 10. It can be observed that in moderate and high corrosion rates cases the structure failure probability has the same curves assumed to exponential function. This explains us a rapid increase when pressure service goes from 2 up to $6 \mathrm{MPa}$, and the relevant values beyond $6 \mathrm{MPa}$ slowly increase failure probability. In the case of low corrosion rate, also a 
slower increase is observed on the probability of failure. Instead of seeing the probability of failure evolution, Figure 9 shows the reliability indexes curves as function of service pressure. Truly, it can be seen that in three cases of corrosion rates, the curves have the same forms and almost as rapid decrease in reliability levels can be observed.

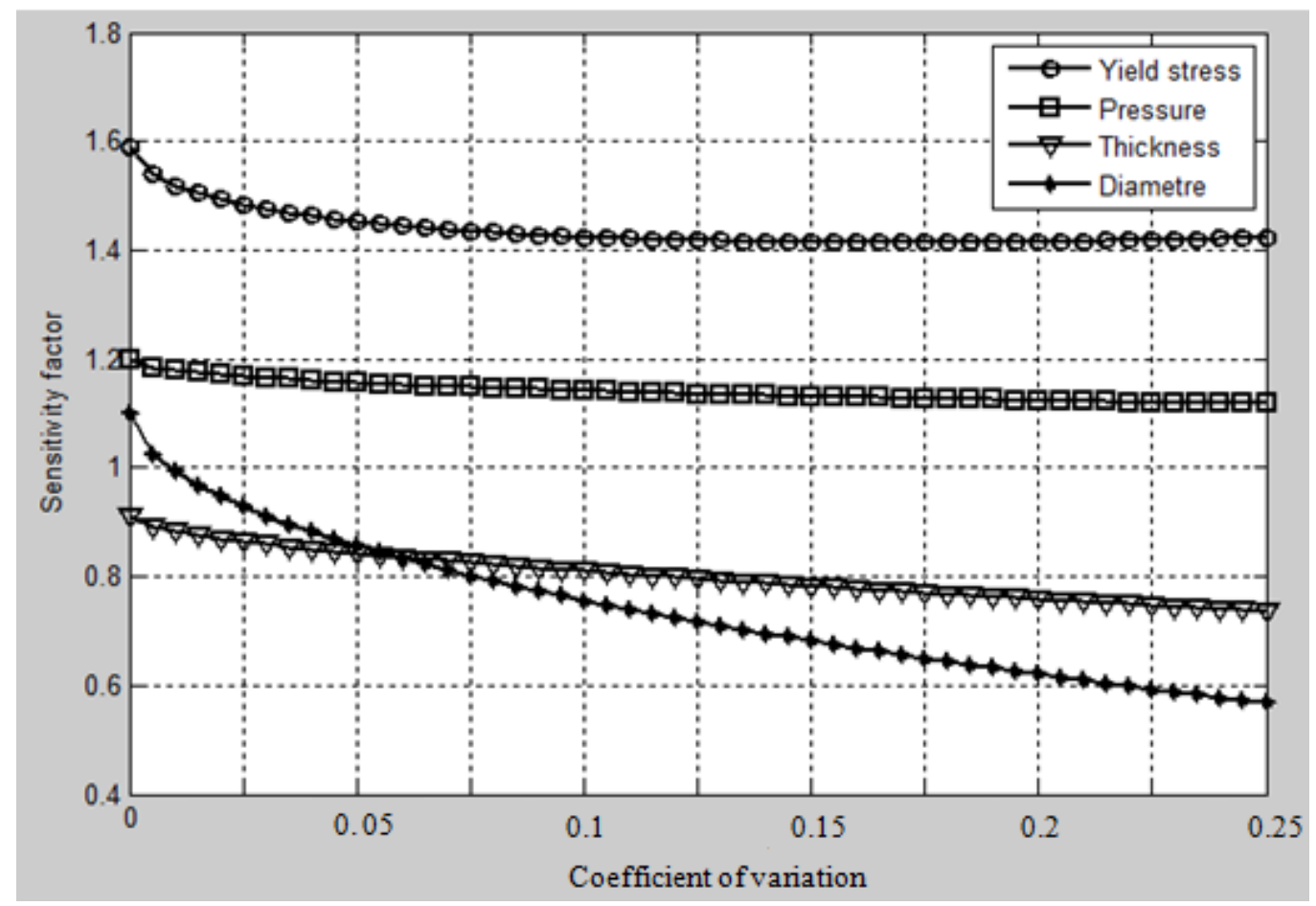

Figure 11. Sensitivity factors of the using model for computing reliability indexes.

Different factors sensitivity effects of the proposed model are illustrated in Figure 11. In fact, the yield stress has the highly important sensitivity following the pressure factor. Less sensitivity can be observed on thickness and diameter factors.

Regarding the results found and shown in Figure 5, Figure 6, Figure 7, Figure 8, Figure 9 and Figure 10, there seems to be a harmful impact on the structure integrity when taking in account both effects of corrosion and residual stress regardless of varying time or service pressure in the proposed model.

\section{Conclusion}

A numerical model of corroded weld joint is proposed by using finite element modulation. The mechanical behavior under corrosion defect as a function of time was studied and an empirical model was also developed. A coupled residual stress model issued from the existing literature was used; the developed probabilistic model has provided corrosion parameters and allowed to predict the real impact on the weld joint lifetime. Reliability indexes and probability of failure for various corrosion rates with and without issued residual stress were computed using Monte Carlo simulation and the first order reliability method. Finally, a sensitivity factor of the failure proposed function caused by the change of the random variable was also studied and discussed. The result of this work can be summarized as:

- A mechanical characterization of the material was carried out experimentally.

- The reliability of a corroding pipe to flange weld joint can be significantly affected by corrosion and residual stress.

- A proportional relationship has been found between probability of failure and corrosion rate.

- The yield stress and pressure service have an important sensitivity factor. 


\section{Acknowledgment}

The authors would like to express their greatest gratitude to the TSS workshop people who have helped and supported this project.

\section{References}

[1] Abid, M., and Siddique, M.: Numerical simulation to study the effect of tack welds and root gap on welding deformations and residual stresses of a pipe-flange joint, International Journal of Pressure Vessels and Piping, 82 (2005), 860-871.

[2] Xinsheng, Z., Wentao, L., Zhengshan, L., Hongyan, He.: Reliability analysis of aged natural gas pipelines based on utility theory, Engineering Review, 35 (2015), 193-203.

[3] Hertelé, S., Cosham, A., and Roovers, P.: Structural integrity of corroded girth welds in vintage steel pipelines, Engineering Structures, 124 (2016), 429-441.

[4] Netto, T.A.: On the effect of narrow and long corrosion defects on the collapse pressure of pipelines, Applied Ocean Research, 31 (2009), 75-81.

[5] Zhang, G.A., and Cheng, Y.F., Micro-electrochemical characterization of corrosion of welded X70 pipeline steel in near-neutral pH solution, Corrosion Science, 51 (2009), 1714-1724.

[6] Chaves, I.A., and Melchers, R.E.: Pitting corrosion in pipeline steel weld zones, Corrosion Science, 53 (2011), 4026-4032.

[7] Mohammadi, F., Eliyan, F.F., and Alfantazi, A.: Corrosion of simulated weld HAZ of API X-80 pipeline steel, Corrosion Science, 63 (2012), 323-333.

[8] Saarinen, A. and Onnela, K.: A method for testing the corrodibility of heat-affected zones in steel, Corrosion Science, 10 (1970), 809-815.

[9] Yang, Y. Yan, B. Li, J. and Wang, J.: The effect of large heat input on the microstructure and corrosion behaviour of simulated heat affected zone in 2205 duplex stainless steel, Corrosion Science, 53 (2011), 3756-3763.

[10] Clover, D. Kinsella, B. Pejcic, B. and De Marco, R.: The influence of microstructure on the corrosion rate of various carbon steels, Journal of Applied Electrochemistry, 35 (2005), 139-149.

[11] C.Q. Ren, N., Xian, X., Wang, L., Liu, Y.P. Zheng.: Susceptibility of welded X80 pipeline steel to corrosion in simulated soil solution, Corros. Eng. Sci. Technol, 47 (2012), 441-445.

[12] Moeinifar, S., Kokabi, A.H., and Hosseini, H.R.: Role of tandem submerged arc welding thermal cycles on properties of the heat affected zone in X80 microalloyed pipe line steel, Journal of Materials Processing Technology, 211(2011), 368-375.

[13] Ji-quan, S., Hui, D., Yong-chun, Z.: Research on mathematical model of thermal deformation resistance of X80 pipeline steel, Materials \& Design, 32 (2011), 1612-1616.

[14] Hyo Kyung, S., Sang Yong, S., Wooyeol, C., Kyungshik, O., Sunghak, L., and Nack, J.K.: Effects of acicular ferrite on charpy impact properties in heat affected zones of oxide-containing API X80 linepipe steels, Materials Science and Engineering: A, 528 (2011), 3350-3357.

[15] Zhou, W.: Reliability evaluation of corroding pipelines considering multiple failure modes and timedependent internal pressure, Journal of Infrastructure System, 17 (2011), 216-224.

[16] Hasan, S., Khan, F., and Kenny, S.: Probability assessment of burst limit state due to internal corrosion, International Journal of Pressure Vessels and Piping, 89 (2012), 48-58.

[17] Teixeira, A.P., Soares, C.G., Netto, T.A., and Estefen, S.F.: Reliability of pipelines with corrosion defects, International Journal of Pressure Vessels and Piping, 85 (2008), 228-237.

[18] Gong, C., and Zhou, W.: Importance sampling-based system reliability analysis of corroding pipelines considering multiple failure modes, Reliability Engineering \& System Safety, 169 (2018), 199-208.

[19] Gong, C., and Frangopol, D. M.: An efficient time-dependent reliability method, Structural Safety, 81 (2019), 101864. 
[20] Gong, C., and Zhou, W.: First-order reliability method-based system reliability analyses of corroding pipelines considering multiple defects and failure modes, Structure and Infrastructure Engineering, 13 (2017), 11, 1451-1461.

[21] Zhou, W., Gong, C., and Hong, H. P.: New perspective on application of first-order reliability method for estimating system reliability, Journal of Engineering Mechanics, 143 (2017), 9, 04017074.

[22] Alamilla, J.L., Sosa, E., Sánchez-Magaña, A., and Andrade-Valencia, R., Contreras A.: Failure analysis and mechanical performance of an oil pipeline, Mater Design, 50 (2013), 766-73.

[23] Kucera, V., and Mattsson, E.: Atmospheric corrosion. In: Mansfeld F, editor. Corrosion mechanics. New York: Marcel Dekker, 1987.

[24] Sahraoui, Y., Khelif, R., and Chateauneuf, A.: Maintenance planning under imperfect inspections of corroded pipeline, International Journal of Pressure Vessels and Piping, 104 (2013), 76-82.

[25] Ruibin, Gou., And Yiliang, Zhang.: Residual stress measurement of new and in-service X70 pipelines by X-ray diffraction method. NDT\&E International, 44 (2011), 387-393.

[26] ASME B31G, Manual for Determining the Remaining Strength of Corroded Pipelines. A Supplement to ANSI/ASME B31 Code for Pressure Piping. 1995.

[27] Naess, A., Leira, B.J., and Batsevych, O.: System reliability analysis by enhanced Monte Carlo simulation, Structural Safety, 31 (2009), 349-355.

[28] Zhou, W.: Reliability evaluation of corroding pipelines considering multiple failure modes and timedependent internal pressure, Journal of Infrastructure System, 17 (2011), 216-224.

[29] Nahal, M., Khelif, R.: Pipelines reliability analysis under corrosion effect and residual stress, Arabian Journal for Science and Engineering, 40 (2015), 11, 3273-3283. 